\title{
Can Revenue and Human Development Promote Happiness: Study on Provinces in Indonesia
}

\author{
Sofyan Rizal ${ }^{1 *}$, Arief Fitrianto ${ }^{2}$ \\ 1,2Universitas Islam Negeri Syarif Hidayatullah Jakarta \\ Email: ${ }^{1}$ sofyan.rizal@uinjkt.ac.id, ${ }^{2}$ arief.fitrijanto@uinjkt.ac.id \\ *) Corresponding author
}

\section{JEL Classification:}

I3

E5

R10

Received: 02 October 2020

Revised: 24 January 2021

Accepted: 02 February 2021

\begin{abstract}
This study seeks to see the relationship between the human development index (HDI) and gross regional domestic product (GRDP) variables on the happiness of economic growth data for provinces in Indonesia. The method used in this research is regression and path analysis. This study proves that happiness is not caused by the income (GRDP) of a region but rather significantly by one of the dimensions of $H D I$, namely the education dimension. The relationship through the variable between using path analysis through the indirect effect of the GRDP intermediary also significantly affects the education dimension. About $60 \%$ of the variable quality of education plays a role in happiness. If the effect is through an intermediary variable, the real influence of the variable quality of education on happiness is 65\%. Other variables such as health and economy, directly or indirectly, do not significantly affect the level of happiness.
\end{abstract}

\section{Keywords:}

Human development, happiness, gross domestic product.

\section{How to Cite:}

Rizal, S., \& Fitrianto, A. (2021). Can Revenue and Human Development Promote Happiness (Study on Provinces in Indonesia). Signifikan: Jurnal Ilmu Ekonomi, 10(1), 113 - 128. doi: http://doi.org/10.15408/sjie. v10i1.17600. 


\section{Introduction}

Central Bureau of Statistics (BPS) released the 2017 Indonesia's happiness index per province, which according to the authors, resulted in an interesting fact that the happiest province was North Maluku province in the first place, while DKI Jakarta was in fourth place in the happiness index. This result is impressive because, according to BPS data, North Maluku is not the province with the highest per capita income or the highest regional PAD in Indonesia. North Maluku is also not the province with the highest Human Development Index in Indonesia.

There were variations in the population's happiness level between provinces in Indonesia, ranging from 67.52 to 75.68. Of the 34 provinces in Indonesia, 24 provinces whose people have an average Happiness Index above the national Happiness Index (70.69) and ten other provinces are below the average national happiness. Furthermore, the three provinces with the highest Happiness Index score were North Maluku (75.68), Maluku (73.77), and North Sulawesi (73.69). Meanwhile, the provinces of Papua, North Sumatra and, East Nusa Tenggara were the three provinces that turned out to have the lowest Happiness Index with each index value of 67.52, 68.41, and 68.98. This result is impressive because, according to BPS data, North Maluku is not the province with the highest per capita income or the highest regional PAD in Indonesia. North Maluku is also not the province with the highest Human Development Index in Indonesia (BPS, 2018).

This fact contradicts the opinion that economic variables such as income, wealth, or employment are essential factors for a good quality of life, individually and socially. More prosperous people usually enjoy better health services, thus having better health rates, longer life expectancies, lower infant mortality rates, and higher access and education. Wealthier people have more freedom to choose. All of this confirms the notion that those who have more opportunities to be happier than those who are poor. This controversial result certainly raises many questions, especially about indicators and measurements of happiness itself. Provinces that are known as low-income provinces have a higher happiness index than relatively more affluent provinces. On the other hand, North Maluku is one of the provinces with the lowest GDP in Indonesia and has the highest happiness index in Indonesia.

The relationship between GDP and Happiness has long been criticized by some experts, giving birth to the Easterlin paradox. Easterlin at least asked in his famous writing in 1974 whether "increasing everyone's income will increase the happiness of all?" when he bases his observations on a measure of happiness that remains unchanged over the long run in a country with a high GDP rate. The relationship between GDP per capita and Happiness becomes a debate among experts in seeing the connection, what factors have a relationship with increasing happiness. GDP per capita, however, cannot be ignored by experts as a determining variable for happiness.

Some research linking specific periods to happiness and income suggests that happiness and income rise and fall together. Connor provides research evidence of how 
the great recession of 2007-09 had a short-term effect, when America's incomes fell, proving that happiness fell to the lowest level on record. Bartolini \& Sarracino (2014) empirically tested and found a relationship between happiness and a decrease in GDP over time, when their research proved that in the long run with a period of at least 15 years and found no significant relationship between GDP and happiness. The researchers also conducted research that looked at income levels for happiness. The study later found that there was a relationship between income (GDP per capita) and happiness levels with various income thresholds ranging from \$10,000 (Frey \& Stutzer, 2002), \$ 12,000 (Kahneman \& Deaton, 2010).

The paradox of the relationship between income and happiness also encourages experts to examine the various factors that influence happiness. Economists suspect and prove various relationships between happiness and several other social variables through several studies. These studies further confirm various factors other than GDP per capita that influence happiness, for example, socio-economic and socio-demographic conditions. Health (physical) (Veenhoven, 1991), age (Blanchflower \& Oswald, 2008), marriage (Stack \& Eshleman, 1998), political, economic, and personal freedom (Veenhoven, 2012), democracy (Dorn et al., 2007), entrepreneurship (Hundley, 2001), voluntary work (Meier \& Stutzer, 2008), social relations (Helliwell et al., 2009), intelligence (Veenhoven \& Choi, 2012). Studies such as Oswald (1997), Gerdtham \& Johannesson (2001), Frey \& Stutzer (2002) emphasize socio-demographic factors to explain happiness. Several other studies include success in education (Blanchflower \& Oswald, 2004) and physical health (Dolan et al., 2008) as causes of happiness.

These various variables emphasize one factor that stands out: the main factor explaining the insignificant phenomenon at a certain level of GDP per capita towards happiness, namely social capital accommodated in Human development. This research paper will focus on two social capital, namely health and education, the Human Development Index dimensions, plus one economic factor: a decent standard of living. The three of them are accommodated in the Indonesian Human Development Index issued by BPS.

Coleman (1988) previous research confirmed one dimension used by this paper, namely education. Student educational attainment will increase life satisfaction. Also, participation in various activities increases students' self-esteem, cognitive abilities, memory, and creativity. Human development will reduce student dropout rates (Behzad, 2002) and increase educational attainment and achievement, increasing happiness (Ghamari, 2012). Another dimension of HDI used in this paper is health. Human development will usually increase health-promoting behaviors (Majeed \& Liqat, 2019; Majeed \& Ajaz, 2018; Kessler, 1997), such as outdoor activities, sports, and social collaboration. These activities lower levels of stress, depression and improve physical and mental health. According to Kawachi et al. (1997), Better health increases happiness both directly and indirectly. Positive health outcomes directly increase happiness levels. Indirectly, healthier individuals work more efficiently and have high productivity, which leads to higher 
per capita income and lower stress levels. Also, healthier students are more active and have higher efficiency. Therefore, good health enhances educational attainment, which is positively related to happiness.

The link between Human development and Happiness can be traced through the sources of happiness. This source of happiness is closely related to improving the quality of life. The connection between the source of happiness and human development can be started from factors considered a source of happiness. The factors that can be considered sources of happiness and indicate the quality of life are; health, education, and unemployment. Several studies link GDP and human development through channels of improving the quality of life. Improved quality of life will make an increase in the human development index. The relationship between GDP and an increase in the quality of life can be detailed as follows: A higher per capita income is always accompanied by an increase in labor productivity, which means more excellent choice in the use of opportunities and time. As Sen (2001) argues, by increasing the freedom to make economic choices, growth has implications for improving people's welfare and quality of life. An increase in GDP is also usually followed by an increase in education and resources for personal development. Economic growth (increased GDP) also leads to higher life expectancy, decreased child mortality, and underweight children (Becker et al., 2005; Easterlin \& Angelescu, 2009).

Several opinions have linked economic growth with happiness that can at least refer to several writings. Several studies admit that there is indeed a close relationship between GDP and happiness because the dimension of happiness related to economic growth (GDP) does have a relationship, but to some extent. For example, linked life expectancy to economic growth, pollution, well-being, unemployment and happiness, increased crime, and happiness (Tella \& MacCulloch, 2008). However, in the GDP per capita, this influence still has limitations, as revealed by Layard's research. In their research, Kahneman \& Deaton (2010) found that when income has passed a certain threshold, the level of happiness does not appear to depend on per capita income. This opinion is also shared by Inglehart et al. (2008).

GDP per capita, HDI, and Happiness, in this context, are reasonable to be seen as things that might influence each other. When GDP per capita is no longer the final goal because it is considered not to accommodate welfare as a whole, GDP growth is only the cause of an economy's ultimate goal. An alternative that is more accommodating in measuring welfare is happiness, so it is exciting to see the various relationships between income, HDI, and happiness. Based on the above phenomena, this study focuses on the relationship between per capita income, the human development index, and its effect on happiness. This research's novelty is how the direct relationship between HDI and happiness, the relationship between GRDP and Happiness, and the GRDP relationship as a variable between HDI and happiness. 


\section{Methods}

The Indonesian human development index compiled by BPS concerns at least three things that are near related to the theory of human development and growth, namely Life Expectancy, Average Length of Schooling, and public consumption. This study uses secondary data obtained from the Central Bureau of Statistics publication on the study variables. Data were collected from all provinces in Indonesia in 2014-2017. The variables used are GDP per capita province, Human Development Index per province, and happiness index.

The data analysis technique uses four methods of analysis, namely descriptive analysis to analyze individual variable data, correlation method (Pearson Correlation / Product Moment) to explain the trend of the two variables studied, regression model method, and path analysis to see the relationship and relationship path of the variables being modeled.

The structural equation in this study is formulated in two sub-structural equations as follows:

a. The equation of the first substructure path:

$$
Y_{1}=\rho Y_{1} X_{1}+\rho Y_{1} X_{2}+\rho Y_{1} X_{3}+\varepsilon_{1}
$$

b. The second substructure path equation:

$$
\mathrm{Y}_{2}=\rho \mathrm{Y}_{1} \mathrm{X}_{1}+\rho \mathrm{Y} 1 \mathrm{X} 2+\rho \mathrm{Y}_{1} \mathrm{X}_{3}+\rho \mathrm{Y}_{2} \mathrm{Y}_{1}+\varepsilon_{2}
$$

The two equations can be seen in the relationship between variables and the relationship path depicted in Figure 1.

Figure 1. $X_{1}, X_{2}$, and $Y_{1}$ to $Y_{2}$ Path Diagrams

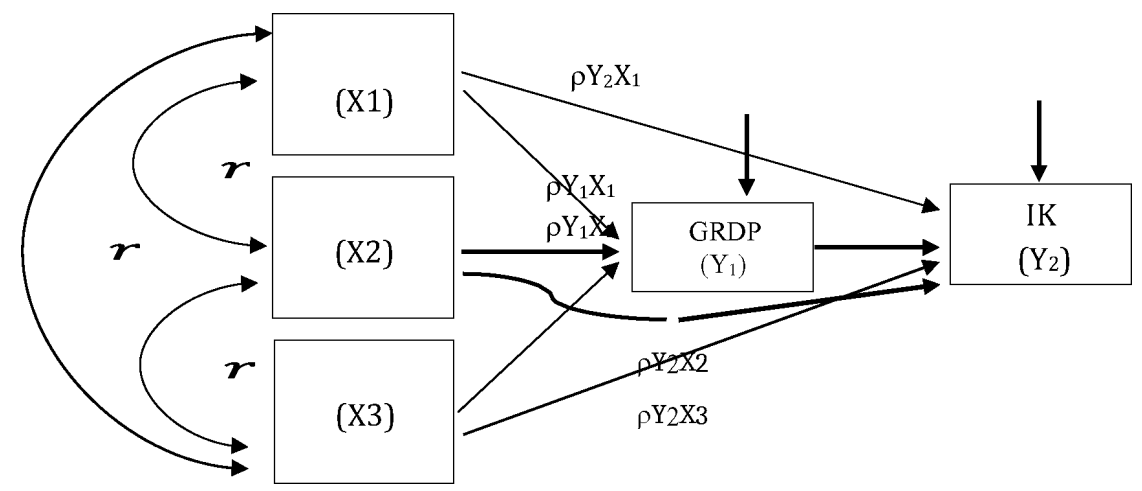

Information:

$\mathrm{X}_{1}=\mathrm{HDI}$ variable in Economic Dimensions

$\mathrm{X}_{2}=\mathrm{HDI}$ variable in education dimension

$\mathrm{X}_{3}=$ HDI Variable in health dimensions

$\mathrm{Y}_{1}=\mathrm{PDRB}$ intervening variable

$\mathrm{Y}_{2}=$ The dependent variable Happiness Index (IK)

$\Gamma \mathrm{X}_{1} \mathrm{X}_{2}=$ Correlation Coefficient $\mathrm{X}_{1}$ to $\mathrm{X}_{2}$

$\rho \mathrm{Y}_{1} \mathrm{X}_{1}=$ Path Coefficient of $\mathrm{Y}_{1} \mathrm{X}_{1}$

$\varepsilon 1,2=$ Other factors that influence $Y_{1}, Y_{2}$ 


\section{Result and Discussion}

The general description of the per capita GRDP conditions of the provinces in Indonesia in 2017 illustrates that there are three main groups, namely the middle to upper group (above 80 million / year), medium (value between 40 million / year to 80 million / year) and middle to lower (under 40 million / year). The middle class and above are occupied by two provinces, namely DKI Jakarta and East Kalimantan. The middle group is occupied by five provinces, namely Riau, Riau Islands, North Kalimantan, Papua, and West Papua. The rest goes to the lower middle.

The Happiness Index value in Indonesia's provinces in 2017 describes a fairly good condition in all provinces. If we use a size range of 0 to 100 for this Happiness index, then using the 3rd quartile (index 50 - 75) as the boundary for good conditions, all provinces are in a good category, and only North Maluku province is in good condition. once (index> 75). The distribution of data in the provinces above illustrates that feeling happy in these provinces is not always in line with the material conditions. Several provinces showing low-income levels turned out to have good levels of happiness. The Human Development Index (HDI) value in provinces in Indonesia in 2017 illustrates a fairly good condition in all provinces. If we use a size range of 0 to 100 for this Happiness index, then using the $3 \mathrm{rd}$ quartile (index 50 - 75) as the boundary for good conditions, all the provinces are in a good category, and the provinces of DKI Jakarta, East Kalimantan, and DI Yogyakarta who are in excellent condition (index> 75).

\section{Correlation Analysis}

Correlation analysis on the three variables of GRDP per capita, HDI, and Happiness Index using product-moment correlation (Pearson) found that the relevant correlations for the three variables occurred only in the HDI and IK variables and the GDP per capita and HDI variables, while between the HDI and Happiness Index (IK) variables, the correlation that was built did not occur significantly.

Table 1. Pearson Correlation between Variables

\begin{tabular}{cccc}
\hline Variable & PDRB & IK & IPM \\
\hline PDRB & 1 & .167 & $.491^{* *}$ \\
IK & & 1 & $.383^{*}$ \\
IPM & & & 1 \\
\hline
\end{tabular}

Source: data processed

Based on Table 1, GRDP has a very weak correlation with the Happiness Index (IK) with a value of 0.167 , in which the Human Development Index (HDI) has a better and moderate correlation to happiness than GRDP. The correlation between GDP per province and HDI variables is in a moderate relationship, meaning that the two 
variables' tendency is neither too strong nor too weak. Many theories have explained the theoretical relationship between the two. Likewise, the results of previous studies also show this. Likewise, in the relationship between the HDI and CI variables, the correlation coefficient also shows intermediate results (0.383), which means that between the two variables tends neither too strong nor weak in the relationship. This is following previous research, which states that there is an influence of the human development index variable on happiness (Costanza et al., 2009; Deaton \& Stones, 2013)

Although HDI and GRDP are significantly correlated and HDI and IK are also correlated, the data findings show that IK is not significantly related to GRDP. This is the same age as previous research, which states that the relationship between income and happiness is weak. This illustrates that the material in the form of capital accumulation, which is reflected in GRDP, is not always in line with its citizens' happiness. Qualitatively, the hypothesis that explains that happiness is in line with the achievement of economic progress, it turns out that the results of this correlation coefficient do not show significant evidence.

Figure 2. Normality P-P Plot Test Models 1 and 2
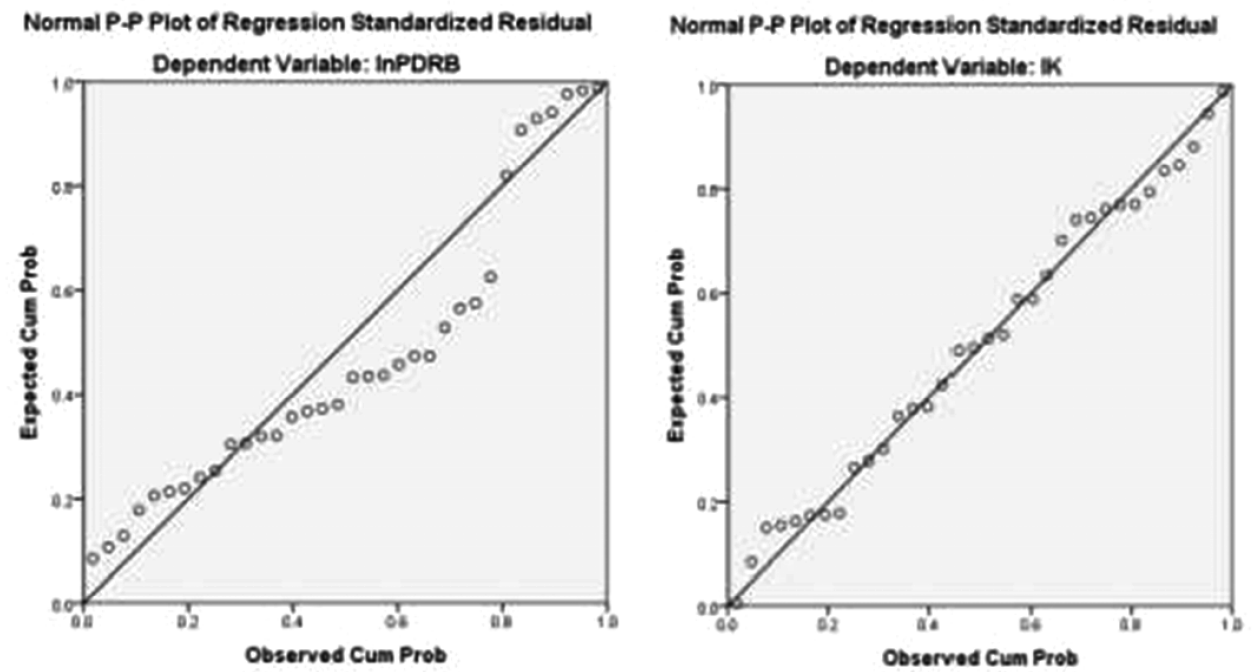

\section{Model Analysis}

Testing the model normality assumption shows that the two models are normally distributed. Normality testing using the Normal P-P Plot on the residual (error) of the two model equations produces a residual pattern that spreads around the diagonal line. This shows that the residuals are distributed following a normal distribution. Table 2 shows the value of multicollinearity, where each HDI variable has a relationship value. The value of the Health variable with an economic index of 0.614. The education index score has a value of 0.531 for the economy, and the Health index is 0.428 for education. 
Table 2. Correlation between Variables

\begin{tabular}{cccccc}
\hline & PDRB & IK & IAHH & IPKK & IEDU \\
\hline PDRB & 1 & .167 & .392 & .492 & .327 \\
IK & .167 & 1 & .207 & .202 & .53 \\
IAHH & .392 & .207 & 1 & .614 & .428 \\
IPKK & .492 & .202 & .614 & 1 & .531 \\
IEDu & .327 & .539 & $.428^{*}$ & .531 & 1 \\
\hline
\end{tabular}

Source: processed data

Multicollinearity testing on the independent variables used by Pearson correlation between independent variables obtained results as shown in Table 2. The correlation coefficient value above the value of 0.8 indicates that there is collinearity between these variables. Conversely, if the correlation coefficient value has a value below the value of 0.8 indicates the absence of multicollinearity in the modeled independent variable. Testing for homoscedasticity using the Glejser test on the two models used can be seen in Table 3. The regression coefficient significance value in the two models, which is not significant, indicates no heteroscedasticity in the model built.

Table 3. Summary of the Glejser test

\begin{tabular}{cccc}
\hline Model 1 & Dependent Variable: absRes1 & Model 2 & Dependent Variable: absRes2 \\
\hline Variable & Sig. & Variable & Sig. \\
IPKK & .346 & IPKK & .524 \\
IEdu & .753 & IEdu & .401 \\
IAHH & .232 & IAHH & .578 \\
& & InPDRB & .970
\end{tabular}

Source: processed data

\section{The goodness of fit test}

The suitability of the structural model built in this study will be tested by testing the model's significance ( $F$ test) and the coefficient of determination, explaining how much the model can describe the variation in the dependent variable. The results of data processing using the SPSS v23 software package, a general test of the model's accuracy, gave significant results in both models. Model 1 with Probability value (P-value $=0.028)<0.05$, then the test decision rejects H0. This result means that the structural model built significantly can be used to model the influence of the $\mathrm{AHH}, \mathrm{PKK}$, and Education variables on GDP per capita.

Based on Table 4, the general test of the second model's suitability also yields a significant value. The probability value $(\mathrm{P}$-value $=0.028)<0.05$ then the test decision rejects H0. This result means that the constructed structural model can be used 
significantly to model the influence of the AHH, PKK, Education, and GRDP per capita variables on the Happiness Index (IK).

Table 4. Test F model structures Model 1 and Model 2

\begin{tabular}{ccccc}
\hline & Model 1 & \multicolumn{3}{c}{ Model 2 } \\
\hline F & Sig. & F & Sig. \\
\hline Regression & 3.484 & .028 & 3.183 & $.028^{\mathrm{b}}$ \\
\hline
\end{tabular}

Source: processed data

Table 5, summarizes the coefficient of determination of the two models. The first model produces a value of $\mathrm{R}^{2}=0.258$, which means that the quality model of human resources with the proxies of $\mathrm{AHH}, \mathrm{PKK}$, and education as its dimensions can explain per capita income behavior by $25.8 \%$. Simultaneously, the rest is explained by other variables that are not included in the model. The second model produces a value of $\mathrm{R}^{2}=0.305$, which means that the quality model of "Happiness" with the Happiness Index (IK) proxy can be explained by AHH, PKK, Education per capita GRDP of $30.5 \%$. In comparison, the rest is explained by other variables that are not included in the model.

Table 5. The Coefficient of Determination of model 1 and model 2

\begin{tabular}{cccc}
\hline & Model 1 & \multicolumn{3}{c}{ Model 2 } \\
\hline $\mathrm{R}$ & $\mathrm{R}^{2}$ & $\mathrm{R}$ & $\mathrm{R}^{2}$ \\
.508 & .258 & $.552^{\mathrm{a}}$ & .305 \\
\hline
\end{tabular}

Source: processed data

\section{Estimated Model Parameters}

Model 1 wants to show how the relationship between IP and GRDP, and model 2 shows the direct relationship between HDI and the happiness index without intermediate variables. In model 1 , the estimation results explain that only the Family Consumption Expenditure (PKK) variable significantly affects the per capita GRDP variable (rejects $\mathrm{H}_{0}$ ) at the level of significant $(\alpha) 10 \%$. The other model variables show less significant results. This indicates that only the quality of human resources from an economic standpoint has a significant impact on welfare quality (as a proxy for GDP per capita). Meanwhile, from the dimensions of education and health, it does not significantly affect it.

In model 2, the estimation results explain that only the education variable significantly affects the IK variable (rejects $\mathrm{H} 0$ ) at the level of significant ( $\alpha$ ) 5\%. The other model variables show less significant results. This indicates that only the quality of human resources in terms of education significantly affects Happiness's quality (using the Happiness Index as a proxy). Meanwhile, PDRB per capita, Family Consumption Expenditure (PKK), and Life Expectancy Rate (AHH) did not significantly affect. This 
finding is also in line with the correlation coefficient values obtained between the HDI and IK variables. This means that the trend/correlation between the HDI and IK variables is confirmed by the regression model made. The trend relationship between the two variables is limited to the trend and the causality relationship. However, this relationship is only significant in the education dimension. This finding is different from previous research, which states that health variables influence happiness (Kawachi et al., 1997; Majeed \& Samreen, 2021; Dolan et al., 2008; Majeed \& Liqat, 2019; Kessler, 1997), but it is in line with research. The education variable has a significant effect on the happiness variable (Coleman, 1988; Behzad, 2002; Ghamari, 2012; Veenhoven \& Choi, 2012).

Table 6. Estimation results of model parameters

\begin{tabular}{cccccc}
\hline & Model 1 & \multicolumn{5}{c}{ Model 2 } \\
\hline Variable & B & Sig. & Variable & $\beta$ & Sig. \\
(Constant) & 6.205 & .001 & (Constant) & 57.801 & .000 \\
IAHH & 3.156 & .255 & InPDRB & .238 & .671 \\
IPKK & 3.502 & .092 & IAHH & .731 & .932 \\
IEdu & -1.001 & .655 & IPPK & -4.773 & .464 \\
& & & IEdu & 22.010 & .003
\end{tabular}

Source: processed data

In the first model, the estimation results explain that only the Family Consumption Expenditure (PKK) variable significantly affects the per capita GRDP variable (rejects $\mathrm{H}_{0}$ ) at the level of significant $(\alpha)$ 10\%. The other model variables show less significant results. This indicates that only the quality of human resources from an economic standpoint has a significant impact on welfare quality (as a proxy for GDP per capita). Meanwhile, from the dimensions of education and health, it does not significantly affect it.

In the second model, the estimation results explain that only the education variable significantly affects the IK variable (rejects $\mathrm{H}_{0}$ ) at a significant $5 \%$ level. The other model variables show less significant results. This indicates that only the quality of human resources in terms of education significantly affects Happiness's quality (using the Happiness Index as a proxy). Meanwhile, GRDP per capita, family consumption expenditure, and life expectancy rate did not significantly affect. This finding is also in line with the correlation coefficient values obtained between the HDI and IK variables. This means that the trend/correlation between the HDI and IK variables is confirmed by the regression model made. The trend relationship between the two variables is limited to the trend and the causality relationship. However, this relationship is only significant in the education dimension. The influence of the Education variable on the Happiness variable is positive. If the Education variable increases by one percent, there will be an increase in the Happiness variable by $22 \%$. 


\section{Path Analysis}

Path analysis in this research is used to determine the relationship between independent variables in influencing the dependent variable. The independent variable directly affects the dependent variable, or through the intervening variable seen from the relationship's coefficient on each of the possible alternative paths from the hypothesized model structure. From the two models formulated, the structural equation is formulated as follows:

Structural Equations I:

$Y_{1}=\rho Y_{1} X_{1}+\rho Y_{1} X_{2}+\rho Y_{1} X_{3}+\varepsilon_{1}$

Which:

$\mathrm{Y}_{1}=\mathrm{GRDP}$

$\mathrm{X}_{1}=$ HDI_Eco

$\mathrm{X}_{2}=$ HDI_Edu

$\mathrm{X}_{3}=$ HDI_Health

$\rho \mathrm{Y}_{1}=$ Path Coeff

The estimated effect of each independent variable that has been standardized for the first model is shown in Table 7. In the first structural model, there are no intervening variables, so that the total effect is the same as the direct effect. The direct effect of the education quality variable on GDP per capita is $7.3 \%$, while other variables influence the rest. The health variable (AHH) directly affects the per capita GRDP variable by $13.2 \%$, while other variables influence the rest. The economic variable (PKK) directly affects the per capita GRDP variable by $37.2 \%$, while other variables influence the rest.

Table 7. Summary of the results of the coefficient of influence for Model 1

\begin{tabular}{cc}
\hline Variable & Standardized Coefficients \\
\hline IAHH & .132 \\
IPPK & .372 \\
IEdu & .073 \\
$\mathrm{e}_{1}$ & $\sqrt{ } 1-0.258=0.86$ \\
\hline
\end{tabular}

Source: processed data

From the three variables being modeled, it was found that the economic variable was the variable that most affected GRDP per capita. These results explain, in general, the HDI variable has a relatively small effect on GRDP per capita, but of the three dimensions of HDI that make up HDI, the economic dimension has the most significant influence. 
Structural Equations 2:

$\mathrm{Y}_{2}=\rho \mathrm{Y} 2 \mathrm{X} 1+\rho \mathrm{Y} 2 \mathrm{X} 2+\rho \mathrm{Y} 2 \mathrm{X} 3+\rho \mathrm{Y} 2 \mathrm{Y} 1+\rho \varepsilon 1+\rho \varepsilon 2$

Which:

$\mathrm{Y}_{2}=$ Happiness index

$\mathrm{Y}_{1}=$ GRDP Per capita

$\mathrm{X}_{1}=$ HDI_Eco

$\mathrm{X}_{2}=$ HDI_Educ

$\mathrm{X}_{3}=$ HDI_Health

$\rho_{y}=$ path coefficient

The results of data processing using the SPSS v23 software package obtained an estimate of the effect of each independent variable that has been standardized for Model 2 is shown in Table 8. There is an intervening variable in the second structural model, namely the per capita GRDP variable so that there are a direct influence pathway and influence through intermediate variables. The total effect is obtained from the sum of the direct and intermediate effects of the relationship between the variables.

Table. 8 Summary of the results of the coefficient of influence for Model 2

\begin{tabular}{lcc}
\hline & Direct Effect $Y_{2}$ & \\
\hline Variable & 0 \\
InPDRB & .077 \\
IAHH & .017 \\
IPKK & -.165 \\
IPend & Effects of $\mathrm{Y}_{2}$ through $\mathrm{Y}_{1}$ & .602 \\
\hline & & $.017 * .077=0.002$ \\
\hline IAHH & $-.165 * .077=-0.013$ \\
IPKK & $.602 * .077=0.046$ \\
IEdu & Total Effect To $Y_{2}$ & \\
\hline IAHH & & 0.02 \\
IPKK & & -0.18 \\
IEdu & 0.65 \\
\hline
\end{tabular}

Source: processed data

The direct effect of the education quality variable on Happiness is $60 \%$, while other variables influence the rest. The health variable directly affects the happiness variable by $2 \%$, while other variables influence the rest. The economic variable directly affects the Happiness variable inversely by $17 \%$, while other variables influence the rest. Meanwhile, 
if the effect is through intermediate variables, then the influence of the quality of education variable on Happiness is $5 \%$, while other variables influence the rest. The health variable affects the happiness variable by $0.2 \%$, while other variables influence the rest. The economic variable affects the happiness variable inversely by $1 \%$, while other variables influence the rest.

The real influence of the education quality variable on Happiness is 65\%. The health variable directly affects the happiness variable by $2 \%$. The economic variable has a total effect on the happiness variable inversely by $18 \%$. The effect of economic variables directly or indirectly on the happiness variable, which has an inverse relationship, is an exciting finding in this path analysis. This explains that the quality of happiness is inversely proportional to human resources' quality in its economic dimension. These findings confirm the Esterlin paradox against which the study was based. From the three variables being modeled, it was found that the education variable was the variable that had the most significant influence on happiness. The total effect value that is greater than the effect value without the intervening variable shows that the intervening variable's predictive model is better than the one without the intervening variable. This means that happiness is obtained through the per capita GRDP route.

This study once again proves that the education variable in this model has a significant effect on happiness. This also strengthens previous research from Coleman (1988), Behzad (2002), Ghamari (2012), and Veenhoven \& Choi (2012), that education is very influential on happiness. The health variable in this model directly affects the Happiness variable. However, it is minimal, namely $1.7 \%$. The economic variable directly affects the Happiness variable inversely by $16.5 \%$., meaning that the greater the economic variable, the lower the level of happiness. This explanation is possible with the expenditure approach, where the effect of inflation is then making expenses bigger, will make happiness decrease (Tella \& MacCulloch, 2007).

\section{Conclusion}

Based on the result, several conclusions were obtained to prove the hypothesis and the pattern of the relationship between variables. This study proves that there is no significant relevance indicating that per capita income growth is an indicator of welfare and happiness. This research shows that the effect of the quality of human resources on welfare with the proxy of GRDP per capita is only explained from the economic dimension. In comparison, happiness can only be explained from the quality of human resources from the dimension of education. Although GRDP per capita is a variable between achieving happiness, from a theoretical point of view, there is an anomaly in human resources quality in terms of material welfare and happiness. The finding of an inverse relationship between the economic dimensions of human resource quality and happiness (IK) confirms the Easterlin paradox, which is the research background. These findings prove that income per capita is not necessarily the main factor that causes happiness, although it is still a factor taken into account in 
measuring the variables that cause happiness. This research also shows that by adding an intermediate variable, in the form of GRDP, the education variable can be a little better in influencing happiness.

The implication of this research for this policy is to increase the level of happiness of its citizens, and the (local) government is more focused on improving the factors that are important and significant in increasing the happiness of its population, namely HDI, especially the level of education and not always oriented to increasing income. However, this study does not suggest neglecting the increase in people's income, because in the short term and at certain income levels, the increase in income is still an essential factor in increasing people's happiness.

\section{References}

Bartolini, S., \& Sarracino, F. (2011). Happy for How Long? How Social Capital and GDP Relate to Happiness over Time. Working Paper No. 2011-60, LISER.

Becker, G. S., Philipson, T. J., \& Soares, R. R. (2005). The Quantity and Quality of Life and the Evolution of World Inequality. American Economic Review, 95(1), 277-291.

Behzad, D. (2002). Social Capital as a Bed for Promoting Mental Health. Seasonally Magazine of Social Welfare, 2(6), 1-15.

Blanchflower, D. G., \& Oswald, A. J. (2004). Well-being Over Time in Britain and the USA. Journal of Public Economics, 88(8), 1359-1386.

Blanchflower, D., \& Oswald, A. (2008). Is Well-being U-Shaped Over The Life Cycle?. Social Science and Medicine, 66(8), 1733-1749.

Coleman, J. S. (1988). Social Capital in The Creation of Human Capital. American Journal of Sociology, 94, 95-120.

Costanza, R., Hart, M., Posner, S., \& Talbert, J. (2009). Beyond GDP: The Need for New Measures of Progress. Pardee Paper No. 4. Pardee Center for the Study of the Longer-Range Future, Boston, MA.

Deaton, A., \& Stones, A. A. (2013). Two Happiness Puzzles. American Economic Review, 103(3), 591-597.

Dolan, P., Peasgood, T., \& White, M. (2008). Do We Know What Makes Us Happy? A Review of The Economic Literature on The Factors Associated with Subjective Well-Being. Journal of Economic Psychology, 29(1), 94-122.

Dorn, D., Fischer, J., Kirchgassner, G., \& Sousa-Ponz, A. (2007). Is it Culture or Democracy? The Impact of Democracy, Income, and Culture on Happiness. Social Indicators Research, 82(3), 505-526.

Easterlin R., \& Angelescu L. (2009). Happiness and Growth The World Over TimeSeries Evidence on The Happiness-Income Paradox. IZA Discussion Paper No. 4060.

Frey, B. S., \& Stutzer, A. (2002). What Can Economists Learn from Happiness Research?. Journal of Economic Literature, 40(2), 402-435. 
Gerdtham, U. G., \& Johannesson, M. (2001). The Relationship Between Happiness, Health, and Socio-economic Factors: Results Based on Swedish Microdata. Journal of Behavioral and Experimental Economics, 30(6), 553-557.

Ghamari, M. (2012). The Relationship of Social Capital and Happiness Among High School Students of Karaj City. International Journal of Academic Research in Business and Social Sciences, 2(1), 353-363.

Helliwell, J. F., Barrington-Leigh, C. P., Harris, A., \& Huang, H. (2009). International Evidence on the Social Context of Well-Being. NBER Working Paper No. 14720.

Hundley, G. (2001). Why Women Earn Less Than Men in Self-Employment. Journal of Labor Research, 22(4), 817-829.

Inglehart, R., Foa, R. Peterson, C., \& Welzel, C. (2008). Development, Freedom and Rising Happiness: A Global Perspective 1981-2006. Perspectives on Psychological Science, 3(4), 264-85.

Kahneman, D., \& Deaton, A. (2010). High Income Improve Evaluation of Life but Not Emotional Well-being. Proceedings of the National Academy of Sciences, 107(38), 16489-16493.

Kawachi, I., Kennedy, B. P., Lochner, K., \& Prothrow-Stith, D. (1997). Social Capital, Income Inequality, and Mortality. American Journal of Public Health, 87(9), 14911498.

Kessler, R. C. (1997). The Effects Of Stressful Life Events on Depression. Annual Review of Psychology, 48, 191-214.

Majeed, M. T., \& Ajaz, T. (2018). Social Capital as a Determinant of Population Health Outcomes: A Global Perspective. Pakistan Journal of Commerce and Social Sciences, 12(1), 52-77.

Majeed, M. T., \& Liaqat, R. (2019). Health Outcomes of Social Inclusion: Empirical Evidence. Pakistan Journal of Applied Economics, 29(2), 201-242.

Majeed, M. T., \& Samreen, I. (2021). Social Capital as a Source of Happiness: Evidence From Across-Country Analysis. International Journal of Social Economics, 48(1), 159-179.

Meier, S., \& Stutzer, A. (2008). Is Volunteering Rewarding in Itself?. Economica, 75(297), 39-59.

Oswald, A. J. (1997). Happiness and Economic Performance. Economic Journal, Royal Economic Society, 107(445), 1815-1831.

Sen, A. (2001). Development As Freedom. New York: Oxford Press.

Stack, S., \& Eshleman, J. R. (1998). Marital Status and Happiness: A 17-Nation Study. Journal of Marriage and the Family, 60(2), 527-536.

Tella, D. R., \& MacCulloch, R. (2007). Happines, Contentment and Other Emotions for Central Banks. NBER Working Paper No. 13622. https://doi.org/10.3386/w13622.

Tella, D. R., \& MacCulloch, R. (2008). Gross National Happiness as an Answer to the Easterlin Paradox?. Journal of Development Economics, 86(1), 22-42. 
Veenhoven, R. (1991). Questions on Happiness: Traditional Topics, Modern Answers, Blind Spots. In Strack, F., Argyle, M. and Schwarz, N. (Eds). Subjective Wellbeing, an Interdisciplinary Perspective, 7-26. London: Pergamon Press.

Veenhoven, R., \& Choi, Y. (2012). Does Intelligence Boost Happiness? Smartness of All Pays More Than Being Smarter Than Others. International Journal of Happiness and Development, 1(1), 5-27 